Revista Brasileira de Meteorologia, v.28, n.1, 25 - 33, 2013

\title{
SENSIBILIDADE DE CONJUNTOS DE NUVENS A VARIAÇÕES DE PARÂMETROS MICROFÍSICOS. PARTE II - INFLUÊNCIA DA CONCENTRAÇÃO DE GOTÍCULAS
}

\author{
ANDRÉ DE SENA PINHEIRO, ALEXANDRE ARAÚJO COSTA \\ Universidade Estadual do Ceará (UECE), Fortaleza, CE, Brasil \\ andresenap@gmail.com, alexandrearaujoc@gmail.com
}

Recebido Julho de 2011 - Aceito Agosto de 2012

\begin{abstract}
RESUMO
Este artigo é o segundo de uma série de quatro artigos com o objetivo de investigar a sensibilidade de sistemas de nuvens convectivas a parâmetros microfísicos. A ferramenta utilizada é uma versão de "modelo de ensemble de nuvens" (Cloud Ensemble Model - CEM) do Regional Atmospheric Modeling System (RAMS), descrita na Parte I. Na Parte II, o foco é a influência da concentração de gotículas, sendo que o modelo de ensemble foi configurado com valores destas concentrações características de ambientes limpos ou de ambientes poluídos. Foi dada ênfase ao impacto das mudanças destas concentrações sobre a distribuição da água nas várias classes de hidrometeoros, no desenvolvimento da precipitação e sobre o balanço radiativo à superfície. Verificou-se que o papel exercido por mudanças na concentração de gotículas sobre estas variáveis pode depender do regime de grande escala ("ativo", com convecção profunda generalizada; ou "suprimido", com inibição da convecção profunda e ocorrência maior de nuvens mais rasas e convecção menos organizada).

Palavras-chave: Convecção Tropical, TOGA-COARE, Modelo de Ensemble de nuvens, Microfísica de Nuvens, Efeito Indireto dos Aerossóis
\end{abstract}

\begin{abstract}
SENSITIVITY OF CLOUD ENSEMBLES TO VARIATIONS IN MICROPHYSICAL PARAMETERS. PART II - INFLUENCE OF DROPLET CONCENTRATION

This article is the second of a series of four articles with aims in investigate the sensitivity of convective cloud systems to microphysical parameters. The tool used in this study is a cloud ensemble version of the Regional Atmospheric Modeling System (RAMS), as described in Part I. In Part II, the focus is on the influence of droplet concentrations, with the cloud ensemble model being configured with values that are typical of clean or polluted environments. Emphasis was given to the impact of those droplet concentration variations on the water partition among the different hydrometeor types, precipitation development and surface radiative budget. It was verified that the role played by droplet concentration changes over these variables might be somewhat dependent on the large-scale regime ("active", with generalized deep convection or "suppressed", with inhibition of deep clouds and dominance of shallower and less organized convection).
\end{abstract}

Keywords: Tropical Convection, TOGA-COARE, Cloud Ensemble Model, Cloud Microphysics, Indirect effect of aerosols

\section{INTRODUÇÃO}

Os efeitos indiretos dos aerossóis podem interferir nas nuvens de formas diferentes: atuando para modificar o seu albedo (efeito do albedo das nuvens ou efeito Twomey) ou influenciando no seu tempo de vida (efeito sobre o tempo de vida das nuvens ou efeito Albrecht) [IPCC, 2007]. Twomey (1974) encontrou que um aumento no número de gotículas acarreta uma maior refletividade nas nuvens. Um aumento na concentração de aerossóis traz um aumento na quantidade de gotículas dentro da nuvem, que tem seu tamanho reduzido, corroborando para um crescimento da refletividade e o albedo referente a essas nuvens, já que as mesmas passam a conter uma grande quantidade de gotículas líquidas que espalham mais radiação solar.

Para o efeito Albrecht, o aumento da concentração de aerossóis na atmosfera reduz a produção de chuvisco, 
aumentando o conteúdo de água líquida (CAL) dentro da nuvem, fazendo com que a mesma aumente de tamanho e demore mais a dissipar-se (Albrecht, 1989), aumentando a cobertura de nuvens e o espalhamento de radiação de onda curta. A inibição do processo de formação da chuva quente em associação com elevadas concentrações de aerossóis foi discutida detalhadamente por diversos autores (Andreae et al., 2004; Costa e Sherwood, 2005; Freud et al., 2008, etc.).

Apesar de serem bastante estudados, os efeitos dos aerossóis ainda são objeto de grandes incertezas. De acordo com os relatórios do IPCC, as estimativas do efeito indireto dos aerossóis iam de 0 a $-2 \mathrm{~W} / \mathrm{m}^{2}$ no Third Assessment Report-TAR e passaram a -0,3 a -1,8 W/m² no Fourth Assessment Report-AR4.

Estas incertezas se devem, em parte, ao fato das medições de aerossóis e das propriedades das nuvens serem localizadas no espaço e tempo, não podendo ser diretamente usadas para inferir os impactos radiativos globais (em cuja escala apenas a cobertura de satélites oferece informações). Além disso, é difícil isolar os efeitos dos aerossóis antropogênicos da variabilidade natural quanto ao raio efetivo e conteúdo de água líquida, causados por mudanças na sua dinâmica e estrutura termodinâmica (Menon et al., 2002).

Outra dificuldade essencial é que os modelos globais não conseguem representar explicitamente a formação de nuvens, recorrendo a artificialismos no tratamento do desenvolvimento da precipitação e da interação daquelas com a radiação solar e terrestre, presentes nas parametrizações de convecção profunda e rasa, cobertura de nuvens e radiação. Uma forma de mitigar esse problema é o uso de um modelo com maior resolução sendo capaz de representar os fenômenos explicitamente, e com os resultados, aperfeiçoar tais parametrizações, como proposto por diversos autores (Randall et al., 1996, Moncrieff et al., 1997) com os chamados modelos de conjunto de nuvens (Cloud Ensemble Model - CEM), descritos em detalhe na Parte I.

A Parte II utiliza o CEM descrito e testado na Parte I para estudar a influência dos aerossóis em nuvens convectivas tropicais. Mais especificamente, visa explorar os possíveis impactos de mudanças nas concentrações de gotículas na formação e no ciclo de vida destas nuvens, bem como, o efeito sobre a precipitação formada e sobre o balanço radiativo, para diferentes condições de estabilidade vertical.

\section{METODOLOGIA: DADOS OBSERVADOS, MODELO NUMÉRICO, SIMULAÇÕES}

Este trabalho utilizou os dados de sondagem sobre a matriz de fluxo intensivo (Intensive Flux Array - IFA) do Tropical Ocean Global / Atmosphere Coupled OceanAtmosphere Response Experiment (TOGA-COARE), coletados durante o período de observação intensiva (Intensive Observing
Period - IOP), descritos na Parte I. Estes dados serviram para alimentar o CEM, tanto no que diz respeito à sondagem inicial, quanto em relação às forçantes de grande escala. No presente artigo, o CEM foi alimentado com as forçantes referentes aos regimes de convecção ativa (terça parte da média dos dados observados, em período não contínuo, do IOP, em que a temperatura de brilho do topo das nuvens é mais baixa) e suprimida (terça parte da média dos dados observados, em que a temperatura de brilho do topo das nuvens é mais alta).

O CEM representou 15 dias de interação dos sistemas de nuvens com as forçantes de grande escala, sendo que os 3 primeiros dias de transiente são descartados e apenas os 12 dias seguintes são utilizados para gerar as estatísticas analisadas neste artigos, em que o primeiro dia de simulação coincide com o primeiro dia do IOP.

A configuração do CEM, para ambos os regimes, são baseadas em Costa et al. (2001) e Costa (2004), com as alterações no modelo RAMS e as escolhas de parametrizações físicas descritas em detalhes na Parte I. A grade contém 1024 pontos na direção x com espaçamento de $1 \mathrm{~km}$ e 70 níveis verticais com resolução variável $(80 \mathrm{~m}$ próximo à superfície, razão de aumento vertical de 1,036 e espaçamento máximo de $600 \mathrm{~m}$ ).

$\mathrm{O}$ esquema de microfísica adotado foi o de Walko et al. (1995), com três valores diferentes para a concentração de gotículas $\left(300 \mathrm{~cm}^{-3}, 1000 \mathrm{~cm}^{-3}, 2000 \mathrm{~cm}^{-3}\right)$. As demais configurações foram idênticas à da simulação de controle descrita na Parte I, isto é, diâmetros especificados de $1 \mathrm{~mm}$ para gotas de chuva, neve, agregados e graupel e $3 \mathrm{~mm}$ para granizo e parâmetro de forma igual a 2 para todas as espécies de hidrometeoros. Adenominação de cada um dos seis experimentos numéricos é indicada por uma letra ("A" para simulações do regime ativo e "S" para simulações do regime suprimido) e por um número que indica diretamente a concentração de gotículas especificada. Por exemplo, A300 simboliza a simulação para o período ativo com concentração de gotículas igual a $300 \mathrm{~cm}^{-3}$ e $\mathrm{S} 1000$ representa a simulação para o período suprimido com concentração de gotículas igual a $1000 \mathrm{~cm}^{-3}$.

\section{RESULTADOS}

A Tabela 1 mostra as médias no domínio do CEM e nos 12 últimos dias de simulação da taxa de precipitação $(\mathrm{mm} / \mathrm{h})$, do condensado total integrado na vertical $\left(\mathrm{kg} / \mathrm{m}^{2}\right)$, e dos fluxos radiativos e de calor sensível e latente $\left(\mathrm{W} / \mathrm{m}^{2}\right)$ em função da concentração para as duas condições de forçante.

Como esperado, há diferenças sensíveis entre os valores dessas variáveis quando se vai do regime ativo para o suprimido, em função do papel dominante exercido pela forçante de grande escala, diferente em cada um deles. A taxa de precipitação média nas simulações do regime ativo $(0,362$ 
Tabela 1 - Taxa de precipitação, condensado e fluxos de radiação e calor nas seis simulações realizadas.

\begin{tabular}{|c|c|c|c|c|c|c|c|}
\hline & A300 & A1000 & A2000 & S300 & $\mathbf{S 1 0 0 0}$ & $\mathbf{S 2 0 0 0}$ \\
\hline \multicolumn{2}{|c|}{$\begin{array}{c}\text { Taxa de Precipitação } \\
\text { (mm/h) }\end{array}$} & 0,372 & 0,372 & 0,362 & 0,148 & 0,142 & 0,139 \\
\hline \multicolumn{2}{|c|}{$\begin{array}{c}\text { Condensado } \\
\text { integrado na vertical } \\
\left(\mathrm{kg} / \mathrm{m}^{\mathbf{2}}\right)\end{array}$} & 0,469 & 0,527 & 0,537 & 0,115 & 0,126 & 0,135 \\
\hline \multicolumn{2}{|c|}{$\begin{array}{c}\text { Fluxo de radiação de } \\
\text { onda curta }\left(\mathrm{W} / \mathrm{m}^{2}\right)\end{array}$} & 63,340 & 69,697 & 64,229 & 246,280 & 244,316 & 242,959 \\
\hline \multirow{4}{*}{$\begin{array}{c}\text { Área } \\
\text { coberta } \\
\text { por } \\
\text { nuvens } \\
(\%)\end{array}$} & total & 99,410 & 99,210 & 99,250 & 68,700 & 69,700 & 75,560 \\
\hline & baixas & 19,140 & 16,230 & 16,840 & 27,480 & 25,310 & 23,270 \\
\hline & médias & 72,540 & 71,120 & 71,260 & 9,810 & 12,600 & 15,170 \\
\hline & altas & 98,500 & 97,540 & 97,730 & 54,500 & 56,010 & 62,500 \\
\hline \multicolumn{2}{|c|}{$\begin{array}{c}\begin{array}{c}\text { Fluxo de radiação de } \\
\text { onda longa }\left(\mathrm{W} / \mathrm{m}^{2}\right)\end{array} \\
\end{array}$} & 448,369 & 447,793 & 447,990 & 424,506 & 425,501 & 426,087 \\
\hline \multicolumn{2}{|c|}{$\begin{array}{l}\text { Fluxo de calor } \\
\text { sensivel }\left(\mathrm{W} / \mathrm{m}^{2}\right)\end{array}$} & 7,680 & 7,949 & 7,821 & 11,528 & 11,148 & 10,770 \\
\hline \multicolumn{2}{|c|}{$\begin{array}{c}\text { Fluxo de calor latente } \\
\left(\mathrm{W} / \mathrm{m}^{2}\right)\end{array}$} & 80,859 & 83,566 & 82,882 & 78,827 & 77,429 & 75,483 \\
\hline
\end{tabular}

a $0,372 \mathrm{~mm} / \mathrm{h}$ ), por exemplo, é tipicamente duas vezes e meia maior do que nas simulações do regime suprimido $(0,139$ a 0,148 $\mathrm{mm} / \mathrm{h}$ ), coerente com um condensado integrado na vertical que aumenta por um fator de quatro vezes ou mais entre um regime e outro (de valores variando de 0,115 a $0,135 \mathrm{~kg} / \mathrm{m}^{2}$ no regime suprimido a valores entre 0,469 e $0,537 \mathrm{~kg} / \mathrm{m}^{2}$ no regime ativo). O impacto na cobertura de nuvens e no fluxo radiativo de onda curta na superfície é também bastante pronunciado. Enquanto as simulações do período ativo exibem valores de cobertura de nuvens próximos a 100\% (com destaque para os valores elevados da cobertura de nuvens altas, associadas às bigornas dos sistemas convectivos), as simulações do período suprimido apresentaram cobertura de nuvens total variando entre $68,7 \%$ (S300) e 75,6\% (S2000). Como consequência do bloqueio da radiação solar pelas nuvens que cobriram inteiramente o domínio do modelo por praticamente todo o tempo de simulação, a média do fluxo incidente de onda curta nestas últimas é tipicamente quase quatro vezes menor no período ativo (de 63,3 a $69,7 \mathrm{~W} / \mathrm{m}^{2}$ ) do que no período suprimido (cerca de 243 a aproximadamente $246 \mathrm{~W} /$ $\mathrm{m}^{2}$ ). Variações menos importantes foram verificadas nos outros termos do balanço energético à superfície. Como esperado, o fluxo de radiação de onda longa para baixo foi maior no caso ativo, devido ao maior efeito estufa promovido pelas nuvens.

Comparando-se as simulações para um mesmo regime, verifica-se que o efeito do aumento na concentrações de gotículas influencia os resultados de maneira similar em cada caso, em diversos aspectos, mas que pode haver diferenças na importância desse efeito ou mesmo mudança de comportamento entre um regime e outro.

O aumento da concentração tanto para o período ativo, quanto para o suprimido acarreta um aumento da quantidade média de condensado e uma redução da taxa de precipitação média, pois a disputa de vapor d'água pelas gotículas aumenta nos casos poluídos, reduzindo o seu tamanho e suprimindo a chuva quente, além de aumentar o tempo de vida da nuvem (efeito Albrecht). Variações no condensado total são maiores do que na precipitação, mas a redução na precipitação no caso mais poluído em comparação com o caso limpo é mais significativa no regime suprimido do que no regime ativo. Com efeito, o condensado total cresce aproximadamente $17 \%$ entre as simulações A300 e A2000, e 16\% entre as simulações S300 e S2000. A precipitação, porém, varia apenas 3\% entre os casos extremos do regime ativo, contra $6 \%$ para o regime suprimido.

De fato, a precipitação é a resposta da convecção às forçantes de grande escala, que umedecem e resfriam o ambiente. No quase-equilíbrio, portanto, a precipitação tem que ser em média igual à taxa de influxo de vapor pelas laterais somada à evaporação à superfície. Como nas simulações deste trabalho, a forçante de grande escala e a TSM (uniforme espacialmente e constante no tempo) são as mesmas para ambos os regimes (ativo e suprimido) e ambos os ambientes (limpo e poluído), a taxa de precipitação é semelhante dentro de um mesmo regime (daí as diferenças percentuais serem pequenas). Em um ambiente limpo, no entanto, a remoção de umidade via precipitação é mais eficiente do que em um ambiente poluído. Desse modo, para se ter uma precipitação semelhante, o ambiente poluído precisa acumular uma maior quantidade de material condensado total, uma vez que a fração desse material qTabeue precipita é menor do que no caso do ambiente limpo, o que explica as variações percentuais bem maiores nessa variável.

Como discutido anteriormente, para o regime ativo, o domínio do modelo é praticamente todo coberto por nuvens 
altas, resultado do desentranhamento de material condensado através das bigornas. Também há variações pequenas, no que diz respeito, à cobertura de nuvens médias, sendo que apenas a simulação A300, mostrou maior incidência de nuvens baixas $(19,1 \%$ contra $16,2 \%$ e $16,8 \%$ nas simulações A1000 e A2000, respectivamente). No caso suprimido, há um aumento significativo da cobertura de nuvens para o ambiente mais poluído (75,6\% em S2000 contra 68,7\% em S300 e 69,7\% em S1000), associado, principalmente, com o aumento expressivo da cobertura de nuvens altas $(62,5 \%$ em S2000 contra 54,5\% em S300 e 56,0\% em S1000). Neste regime, há uma variação significativa na cobertura de nuvens médias, com maiores valores em S2000 e, como no regime ativo, uma maior cobertura de nuvens baixas ocorre no ambiente limpo (27,5\% em S300 contra 25,3\% em S1000 e 23,3\% em S2000).

Apesar da variação da quantidade de água condensada seguir o que se esperava quando há um aumento na concentração de gotículas, a radiação de onda curta aparece surpreendentemente menor para A300 (com A1000 apresentado o maior valor entre as três simulações). O fato de todos os casos (A300, A1000 e A2000) apresentarem cobertura de nuvens próxima a $100 \%$, seria suficiente fazer com que os fluxos de radiação fossem similares, mas não que os mesmos se comportassem de maneira invertida, pelo menos em relação a A300 e A1000. Além do aumento de cobertura de nuvens baixas no caso limpo, uma possível explicação seria uma diferença de comportamento nos sistemas de nuvens nos casos limpo e poluído ao longo do dia e da noite (já que, para o balanço de radiação de onda curta só interessam diferenças entre os dois casos no condensado médio durante o dia). De fato, durante o dia, a diferença no condensado total entre os ambientes no regime ativo é pequena, como mostra a Tabela 2, tendo o ambiente poluído (A1000) somente em torno de $4 \%$ mais condensado durante as 4 horas em torno do meio dia local, enquanto que, à noite, essa diferença sobe para quase 19\%. Já para o período suprimido, essa diferença alcança valores em torno de $13 \%$. Tal resultado sugere que as interações nuvemradiação são fundamentais para a compreensão desse fato.

Para A1000, uma maior quantidade de condensado é formada durante o período da noite, enquanto que para A300, isso se dá durante o dia. Tal fato ocorre associado à área coberta por nuvens baixas, que é menor à noite para $\mathrm{A} 1000$ e durante o dia para A300. Já o caso suprimido apresenta mais condensado à noite em ambas as situações (S300 e S1000).

A seguir, analisou-se como as variações na concentração afetam a distribuição vertical média do condensado total e das diferentes espécies de hidrometeoros: água de nuvem, água de chuva, gelo leve (soma de agregados, gelo primário e neve) e gelo denso (soma de graupel e granizo). A Figura 1 mostra o perfil vertical para a diferença entre ambientes poluídos (concentrações iguais a 1000 e $2000 \mathrm{~cm}^{-3}$ ) e o ambiente limpo (concentração $300 / \mathrm{cm}^{-3}$ ) para essas espécies no caso ativo.

Nota-se que a razão de mistura de água de nuvens (Figura 1a) aumenta substancialmente nas simulações A1000 e A2000 em comparação com A300. A diferença entre simulações poluídas e A300 alcança valores maiores que $0,1 \mathrm{~g} / \mathrm{kg}$ próximo a $5 \mathrm{~km}$ de altitude, sendo mais acentuada em A2000. Isso ocorre porque, em um ambiente com maior população de núcleos de condensação, o vapor, ao se condensar, se distribui entre uma maior número de gotículas de menores dimensões, se comparado a um ambiente limpo, inibindo tanto o crescimento das gotículas, quanto formação de chuva quente. Como consequência, há um acúmulo maior de água de nuvem em ambientes poluídos. Já a razão de mistura de água de chuva (Figura 1b) é bastante similar nas três simulações (diferenças máximas próximas de $0,003 \mathrm{~g} / \mathrm{kg}$ numa altitude de aproximadamente $5 \mathrm{~km}$ ), o que é coerente com o fato de ambientes poluídos serem menos

Tabela 2 - Condensado e cobertura de nuvens nos períodos diurnos e noturnos para as simulações realizadas.

\begin{tabular}{|c|c|c|c|c|c|c|c|}
\cline { 3 - 8 } \multicolumn{2}{|c|}{} & $\begin{array}{c}\text { Condensado } \\
\left(\mathbf{k g} / \mathbf{m}^{2}\right)\end{array}$ & $\begin{array}{c}\text { Cobertura } \\
\text { total de } \\
\text { nuvens (\%) }\end{array}$ & $\begin{array}{c}\text { Área coberta } \\
\text { por nuvens } \\
\text { altas }(\%)\end{array}$ & $\begin{array}{c}\text { Área coberta } \\
\text { por nuvens } \\
\text { medias }(\%)\end{array}$ & $\begin{array}{c}\text { Área coberta } \\
\text { por nuvens } \\
\text { baixas (\%) }\end{array}$ & $\begin{array}{c}\text { Taxa de } \\
\text { precipitação } \\
(\mathbf{m m} / \mathbf{h})\end{array}$ \\
\hline \multirow{3}{*}{ A300 } & Dia & 0,490 & 99,300 & 98,360 & 73,320 & 17,650 & 0,410 \\
\cline { 2 - 8 } & Meio-dia & 0,499 & 99,450 & 98,410 & 72,340 & 17,920 & 0,415 \\
\cline { 2 - 8 } & Noite & 0,447 & 99,510 & 98,610 & 71,740 & 20,630 & 0,333 \\
\hline \multirow{4}{*}{ A1000 } & Dia & 0,523 & 98,830 & 96,350 & 69,700 & 16,660 & 0,363 \\
\cline { 2 - 8 } & Meio-dia & 0,519 & 98,710 & 95,880 & 67,350 & 16,010 & 0,363 \\
\cline { 2 - 8 } & Noite & 0,531 & 99,580 & 98,730 & 72,530 & 15,970 & 0,381 \\
\hline \multirow{3}{*}{$\mathbf{S 3 0 0}$} & Dia & 0,105 & 64,680 & 52,190 & 10,200 & 23,140 & 0,124 \\
\cline { 2 - 8 } & Meio-dia & 0,111 & 62,560 & 52,060 & 10,050 & 20,070 & 0,152 \\
\cline { 2 - 8 } & Noite & 0,125 & 72,690 & 56,780 & 9,430 & 31,810 & 0,171 \\
\hline \multirow{3}{*}{$\mathbf{S 1 0 0 0}$} & Dia & 0,118 & 66,560 & 54,930 & 11,920 & 21,540 & 0,129 \\
\cline { 2 - 8 } & Meio-dia & 0,128 & 63,790 & 53,770 & 11,000 & 18,550 & 0,154 \\
\cline { 2 - 8 } & Noite & 0,132 & 72,780 & 57,080 & 13,250 & 29,080 & 0,156 \\
\hline
\end{tabular}


a)

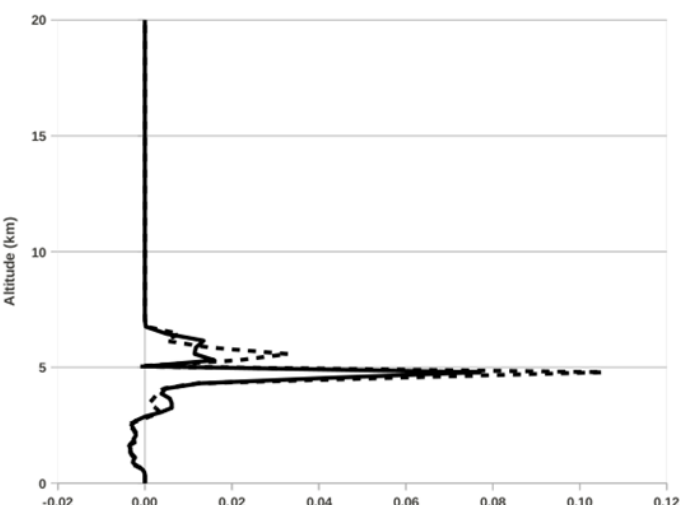

c)

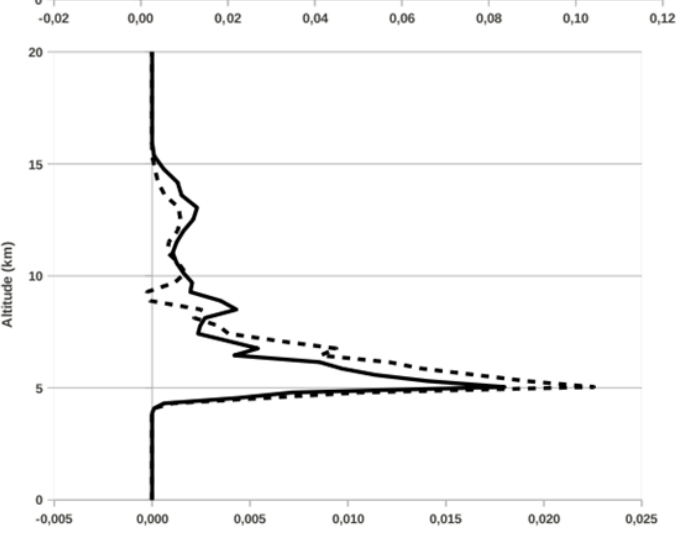

b)

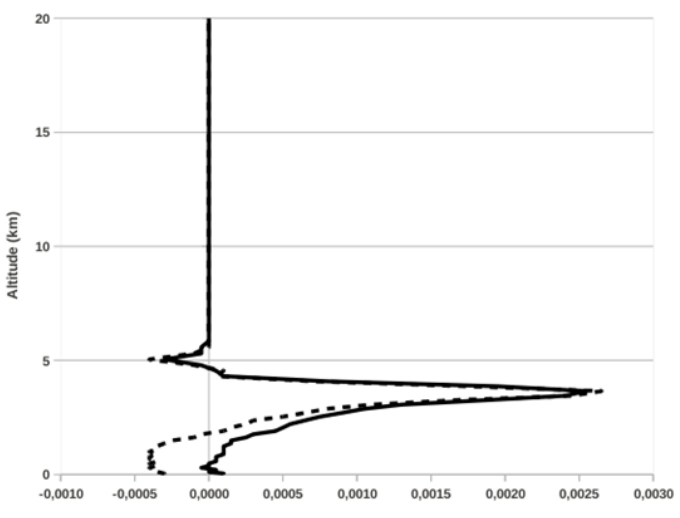

d)

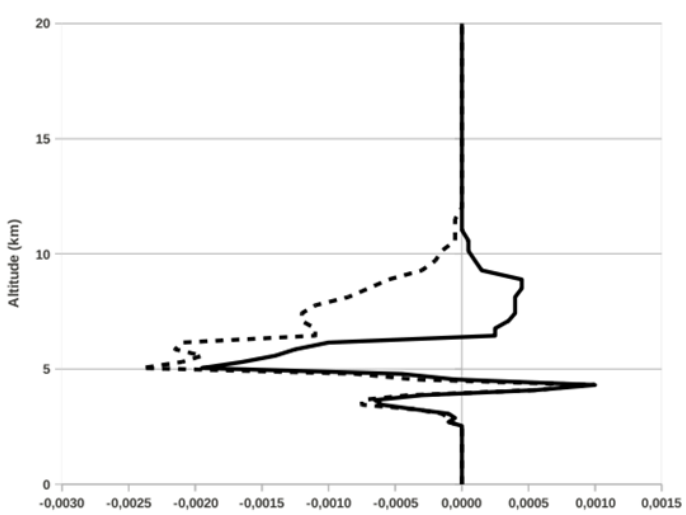

Figura 1 - Diferenças na razão de mistura de (a) água de nuvem, (b) água de chuva, (c) gelo leve e (d) gelo pesado para concentrações 1000/cm³ - 300/ $\mathrm{cm}^{3}$ (contínuo) e $2000 / \mathrm{cm}^{3}-300 / \mathrm{cm}^{3}$ (tracejado) para o período ativo. Os valores nos eixos das abscissas medem a razão de mistura em g/kg e as ordenadas medem a altitude em $\mathrm{km}$.

eficientes na produção de chuva, tendo, portanto, que acumular mais material condensado na forma de água de nuvem para produzir a mesma precipitação. As figuras seguintes mostram o perfil vertical para a diferença entre ambientes poluídos (concentrações iguais a 1000 e $2000 / \mathrm{cm}^{3}$ ) e o ambiente limpo (concentração 300/cm ) para as espécies gelo leve (gelo primário + neve + agregados) e gelo pesado (graupel e granizo) para o período ativo. No que diz respeito ao gelo leve, as maiores diferenças estão próximas de $0,03 \mathrm{~g} / \mathrm{kg}$, sendo sua ocorrência claramente maior nas simulações A1000 e A2000 (Figura 1c). Isso ocorre devido à maior quantidade de água de nuvem, que permanece em suspensão devido à inibição da formação de chuva quente. Em consequência, mais material líquido é levado para altos níveis favorecendo a formação de cristais de gelo. Já para o caso do gelo pesado (diferenças chegando a cerca de $-0,002 \mathrm{~g} / \mathrm{kg}$ ), particularmente para A2000, há uma redução em relação a A300 (Figura 1d). Como o surgimento de graupel se dá através do processo de encrostamento (riming) que resulta da coleta de gotículas por cristais de gelo, este resultado é aparentemente contraditório com o fato de que as simulações de ambientes poluídos possuem maiores razões de mistura, tanto de água de nuvem, quanto de "gelo leve". Entretanto, é preciso lembrar que quanto mais poluído o ambiente, mais reduzido é o diâmetro médio das mesmas. Sendo assim, as simulações poluídas podem conter gotículas de diâmetro tão pequeno, que a eficiência de colisão entre elas e os cristais se reduz, inibindo o encrostamento. Assim, mesmo com maiores quantidades de gelo leve e de água de nuvem, menos graupel e granizo será formado. Daí, mesmo havendo mais material em fase líquida disponível para ser convertido em gelo, este acaba se limitando, em sua maioria, a gelo leve.

A Figura 2 mostra as mesmas diferenças, mas para o período suprimido. Vê-se que a razão de mistura de água de nuvem (Figura 2a), com maiores diferenças em torno de $0,015 \mathrm{~g} / \mathrm{kg}$ é claramente maior para S1000 e S2000 quando comparada com S300. É interessante perceber que, para S2000, o aumento na razão de mistura de água de nuvem em relação a S300 ocorre em altitudes maiores, comparativamente a S1000. Já para a água de chuva (Figura 2b), as diferenças na razão de mistura são muito pequenas (diferenças mais significativas em torno de $-0,0006 \mathrm{~g} / \mathrm{kg}$ ). As explicações para estas diferenças são semelhantes àquelas apresentadas para a comparação das razões de mistura de água de nuvem e água de chuva nos experimentos A1000, A2000 e A300. Para S1000, o gelo leve apresenta pequena diferença em comparação com S300 (valores de pico em torno de $0,001 \mathrm{~g} / \mathrm{kg}$ para altitude de aproximadamente 5 


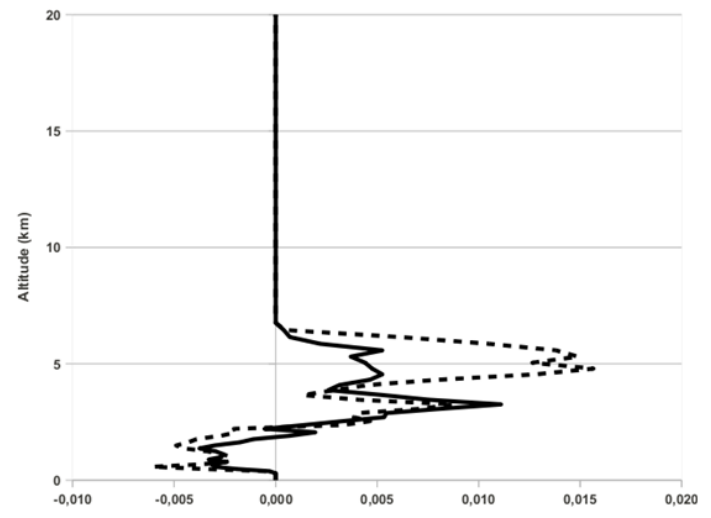

a)

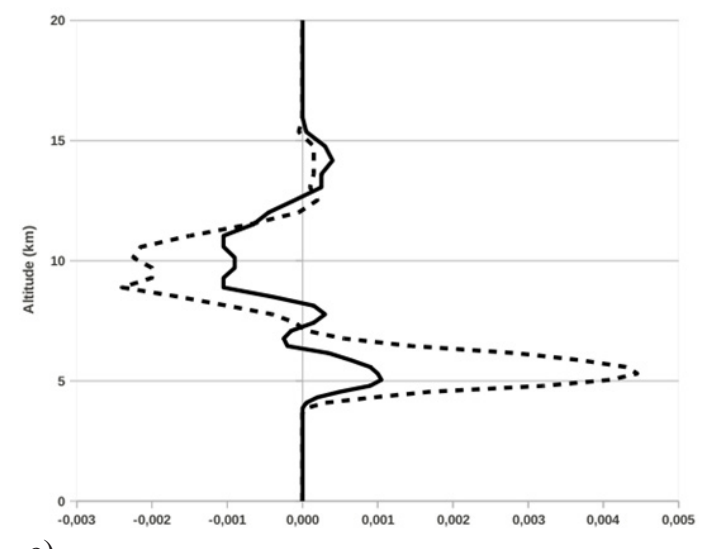

c)

Figura 2 - Como na Figura 1, mas para o período suprimido.

$\mathrm{km})$, sendo essa diferença ligeiramente maior para S2000, com máxima diferença em torno de $0,004 \mathrm{~g} / \mathrm{kg}$ para a mesma altitude (Figura 2b). Para S1000 e S2000, as diferenças para a razão de mistura de gelo denso, quando comparada com S300 são pequenas, contudo, há um padrão onde o gelo denso aparece em menor quantidade em níveis mais altos e maior quantidade em níveis mais baixos na simulação para ambiente limpo.

Alguns dos resultados mostrados evidenciam a importância da interação entre nuvens e radiação, particularmente aqueles mostrados por meio das Tabelas 1 e 2 .

Neste contexto, é importante compreender porque a convecção noturna tende a ser favorecida sobre oceanos tropicais. À noite, o topo da nuvem está mais frio que a região entre nuvens, daí esta última tem uma emissão de radiação de onda longa maior que a nuvem como um todo. À medida que emite essa radiação, $o$ ar contido na região entre as nuvens se resfria, adquire movimento descendente e diverge na superfície do oceano, forçando convergência na região coberta por nuvens e alimentando as mesmas, favorecendo o seu desenvolvimento vertical (Gray e Jacobson, 1977). Em contrapartida, durante o dia, o topo da nuvem absorve radiação solar e, ao haver aquecimento, produz uma estabilização, inibindo movimentos
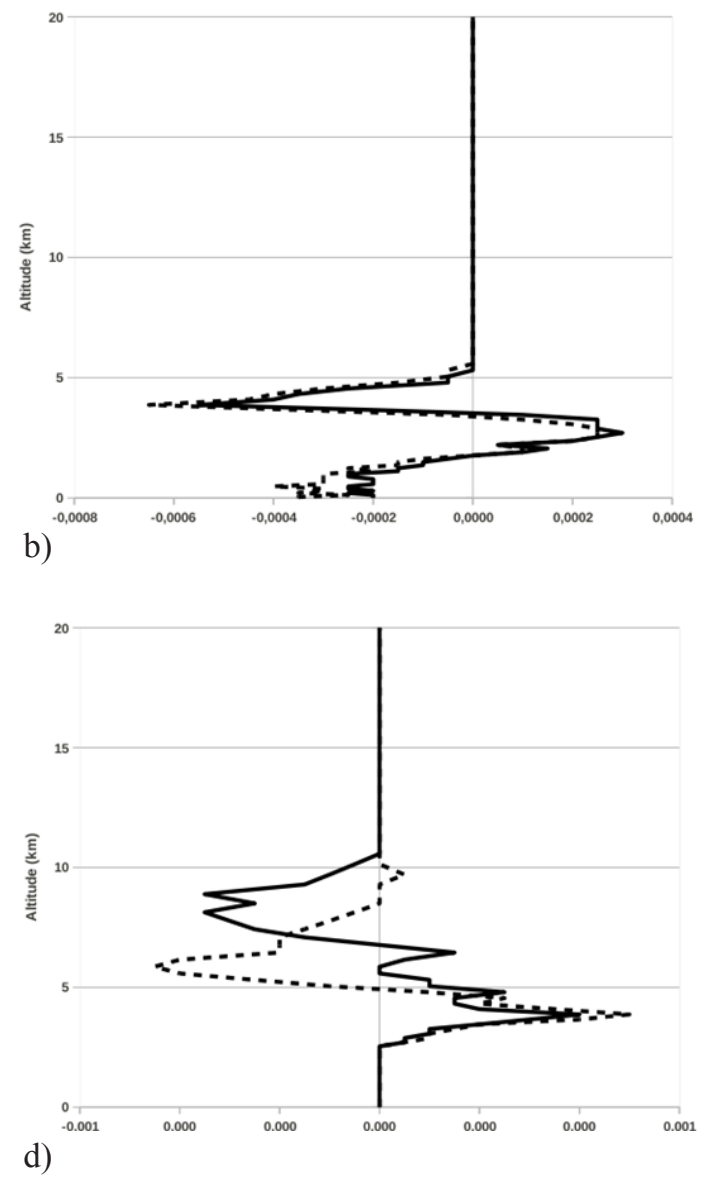

verticais ascendentes e o crescimento da nuvem (Randall et al., 1991). Estes processos aparecem esquematizados na Figura 3.

É importante notar que no caso ativo, praticamente todo o domínio fica coberto por nuvens do tipo cirros. Então, a subsidência forçada pelo resfriamento radiativo nas colunas sem nuvem, que induziria mais convecção noturna em comparação com o dia, tende a desaparecer. Este processo, porém, pode ser percebido no período de menor atividade convectiva (caso suprimido), no qual pelo menos $30 \%$ da área do domínio está inteiramente livre de nuvens, tanto em S300, quanto em S1000. Isso parece explicar porque a convecção noturna para A300 não é mais intensa do que a convecção diurna (ao contrário), ao passo que no caso suprimido, temos, como esperado pela teoria, mais convecção à noite do que durante o dia em todas as simulações.

A cobertura de nuvens também tem influência na precipitação dos dois regimes mostrando uma relação inversa entre eles. No caso ativo, quanto menos nuvens baixas, mais chuva é gerada na simulação, enquanto que no caso suprimido, uma maior quantidade de nuvens baixas favorece a precipitação. Isso ocorre provavelmente porque no regime ativo, a chuva é praticamente toda proveniente de sistemas convectivos profundos, seja através da chuva convectiva, seja através da 
a)

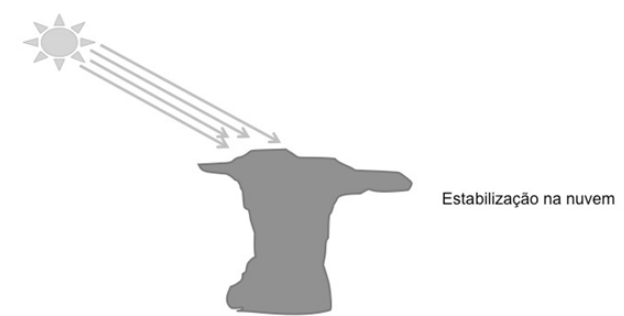

Superficie do oceano (TSM quase constante) b)

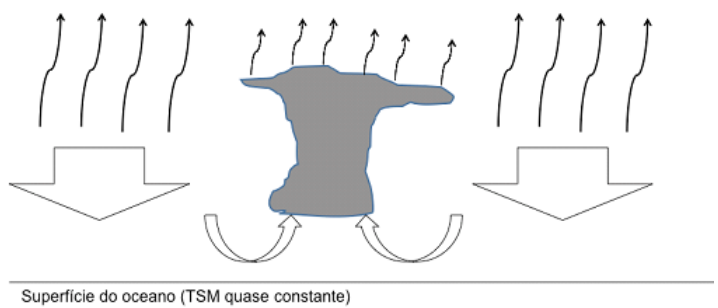

Figura 3 - Diagrama esquemático representando processos de interação nuvem-radiação que interferem no ciclo diurno da convecção sobre os oceanos tropicais. Durante o dia (a) a absorção de radiação solar no topo das nuvens leva a seu aquecimento, produzindo estabilização e detendo o desenvolvimento da convecção. À noite (b), o topo frio das nuvens convectivas irradia menos infravermelho do que a vizinhança sem nuvens que, ao resfriar mais rapidamente, adquire movimento subsidente que, por sua vez, força mecanicamente movimento ascendente nas colunas com nuvens, acelerando o desenvolvimento da convecção. Ver texto para mais detalhes.

chuva estratiforme a partir das bigornas. Neste caso, quanto maior a atividade convectiva nesses sistemas, maior tende a ser o movimento subsidente compensatório em suas vizinhanças, inibindo o desenvolvimento de nuvens rasas. Já no caso suprimido, parcela significativa da chuva parece vir de nuvens mais baixas, especialmente em condições limpas.

Ainda que o efeito da cobertura de cirros seja suficiente para esclarecer o não favorecimento da convecção noturna em A300, não explica porque o seu comportamento é oposto ao de A1000 e das simulações suprimidas, pois na verdade em A300 a convecção é favorecida durante o dia. Uma possível hipótese para essa diferença está no fato de as correntes ascendentes em A300 serem, provavelmente, mais fracas do que em A1000 e A2000, devido à remoção de parte do material pela chuva quente, produzida via colisão-coalescência, não o deixando disponível para liberação de calor latente na fase de gelo. Assim, devemos esperar correntes ascendentes mais intensas nos núcleos convectivos nos casos poluídos, impondo mais subsidência ao redor, inibindo, no caso poluído "ativo", a nebulosidade baixa e média. Esta hipótese é corroborada com o que é mostrado na Figura 1c, que mostra uma maior ocorrência de gelo nas simulações de ambiente poluído no regime ativo. Uma maior formação de gelo implica em uma maior liberação de calor latente nos núcleos ascendentes das nuvens convectivas, impondo mais subsidência à vizinhança.

\section{CONSIDERAÇÕES FINAIS}

A interação dos aerossóis com a atmosfera vai desde o espalhamento e absorção da radiação solar incidente no chamado efeito direto até a formação de nuvens, que regulam o balanço energético global, o que é denominado de efeito indireto. Entretanto, o papel do efeito indireto dos aerossóis não é representado de maneira apropriada em modelos globais, devido ao fato de a escala de nuvens ser muito menor do que a resolução dos modelos utilizados na investigação dos fenômenos climáticos, sendo assim, fonte de grandes incertezas. Neste trabalho são avaliados dois aspectos dessas incertezas: o efeito da concentração de partículas e a influência do gelo. A plataforma utilizada foi um modelo de ensemble de nuvens (Cloud Ensemble Model), que resolve explicitamente os processos em escala de nuvens. Neste caso, a limitação do modelo fica por conta do fato de que estes efeitos não interagem com a circulação de grande escala, sendo esta prescrita, ou seja, introduzida como um forçante externo ao CEM.

No que diz respeito à concentração de gotículas, como esperado, houve um aumento da quantidade de material condensado em suspensão na atmosfera (efeito Albrecht ou segundo efeito indireto dos aerossóis). No entanto, o impacto do aumento do condensado sobre a radiação solar incidente sobre a superfície em condições poluídas mostrou ser dependente do forçante advectivo de grande escala (regime ativo versus suprimido). No regime suprimido, foi encontrado que o condensado aumenta durante a noite e diminui durante o dia, o que é coerente com a teoria que prevê uma maior subsidência na região entre nuvens, causada por um maior resfriamento por emissão de radiação de onda longa nessa região, proposta por Gray e Jacobson (1977). Em contrapartida, também no caso suprimido, durante o dia, a maior absorção de radiação solar pelo topo da nuvem, leva a um aquecimento na porção superior da camada, produzindo uma estabilização, que inibe movimentos verticais ascendentes e o desenvolvimento vertical da nuvem como sugere Randall et al. (1991). Coerente com isso, de S300 para S1000 verificou-se uma maior atenuação da radiação solar incidente, o que está de acordo com as expectativas em torno dos efeitos indiretos dos aerossóis (efeito Twomey e efeito Albrecht)

No entanto, em A300, não se verifica uma convecção noturna mais intensa e, pelo contrário, durante o dia a convecção é fortalecida. Vale salientar que nessa simulação, e também em A1000, o domínio praticamente todo é coberto por nuvens do tipo cirros, produzidas por desentranhamento de material condensado a partir das bigornas das nuvens convectivas 
profundas, e com isso, a subsidência forçada pelo resfriamento radiativo nas colunas sem nuvem, fato que induziria uma maior convecção noturna em comparação com o dia, acaba por desaparecer, em virtude do efeito estufa que é produzido por essas nuvens.

No caso do regime ativo, uma hipótese, que pode explicar o fato de a radiação solar incidente à superfície ser menor no caso limpo do que no caso poluído, seria as correntes ascendentes em A300 aparecerem com menos intensidade do que em A1000. Isto ocorreria devido à remoção de parte do material condensado na forma de chuva quente, ou seja, através da conversão direta de água de nuvem em água de chuva, diminuindo a liberação de calor latente na fase de gelo. Assim, seriam esperadas correntes ascendentes mais intensas nos núcleos convectivos para os casos poluídos, resultando em maior subsidência ao redor da nuvem.

Todavia, entendemos que ainda é necessário investigar vários outros aspectos dos sistemas de nuvens simulados, incluindo a distribuição da intensidade das correntes ascendentes, o fluxo de massa associado às nuvens e o particionamento entre as componentes convectiva e estratiforme. Adicionalmente, é necessário acompanhar com mais atenção a evolução dos sistemas de nuvens individuais, para melhor compreender o ciclo diurno da convecção tropical, e como a modificação das propriedades microfĩsicas desses sistemas, em resposta a mudanças antropogênicas com relação aos aerossóis, pode alterar o balanço de radiação na superfície.

Tanto em Gray e Jacobson (1977) como em Randall et al. (1991), no ciclo diurno da convecção tropical profunda é assumida a preexistência de sistemas convectivos como afirma Chen e Houze Jr. (1997). Ainda segundo estes autores, o estudo baseado somente na interação das nuvens com a radiação apresenta apenas explicações parciais da variabilidade da convecção durante o dia, devendo ser estudados também a formação, crescimento e dissipação dos sistemas convectivos, bem como, sua interação com a superfície do oceano e a camada limite atmosférica.

Em geral, mostrou-se que os efeitos indiretos dos aerossóis são dependentes do regime de grande escala, sendo que o chamado efeito Albrecht (aumento da cobertura de nuvens em consonância com aumento do condensado total) ficou mais evidente na simulação em que a existência de uma região sem nuvens cirros esteve presente, isto é, no regime dito suprimido. Ali, de fato, menos radiação solar atingiu a superfície no caso poluído. Durante o regime ativo, no entanto, a ocorrência generalizada de nuvens altas produzidas por desentranhamento de material condensado no topo dos sistemas convectivos impede que esse efeito se manifeste.

Como há interações complexas entre nuvens e radiação (aqui discutidas e simuladas) e entre as nuvens e a circulação geral atmosférica, é possível que uma representação realmente adequada dos efeitos indiretos dos aerossóis somente seja possível através de uma plataforma de modelagem que explicitamente represente a circulação de grande escala e a formação de nuvens e sua interação com a radiação. Como modelos de ensemble de nuvens dependem de uma forçante de grande escala prescrita, e a grande maioria dos modelos de circulação geral disponíveis representam muito precariamente a formação de nuvens, nenhum dos dois se mostra como uma alternativa adequada. A implementação da chamada "superparametrização", isto é, a introdução de um modelo de ensemble de nuvens em cada coluna de um GCM aparece como uma possibilidade enquanto simulações globais com resolução da ordem de $1 \mathrm{~km}$ não sejam possíveis. Esta é uma das estratégias possíveis para desenvolvimento do Modelo Brasileiro do Sistema Climático Global.

\section{AGRADECIMENTOS}

O presente trabalho foi financiado pelo $\mathrm{CNPq}$, através do projeto CONBINE (Convecção no Nordeste Brasileiro: Interações em Múltiplas Escalas), processo 620057/2008-4. $\mathrm{O}$ primeiro autor agradece à Fundação Cearense de Apoio ao Desenvolvimento Científico e Tecnológico - FUNCAP - pela concessão de bolsa de mestrado para desenvolvimento de seus trabalhos junto ao Mestrado Acadêmico em Ciências Físicas Aplicadas da Universidade Estadual do Ceará.

\section{REFERÊNCIAS}

ALBRECHT, B. A. Aerosols, cloud microphysics, and fractional cloudiness, Science. v. 245, p. 1227-1230, 1989.

ANDREAE, M. O.; ROSENFELD, D.; ARTAXO, P.; COSTA, A. A.; FRANK, G. P.; LONGO, K. M.; SILVA DIAS, M. A. F. Smoking Rain Clouds over the Amazon. Science, v. 303. p 1337-1342, 2004.

CHEN, S. S.; HOUZE, R. A. Jr. Diurnal variation and life cycle of deep convective systems over the tropical Pacific warm pool. The Quarterly Journal of the Royal Meteorological Society, v. 123, p. 357-388, 1997.

COSTA, A. A.; COTTON, W. R.; WALKO, R. L.; PIELKE Sr., R. A. SST Sensitivities in Multiday TOGA COARE Cloud-Resolving Simulations. Journal of the Atmospheric Sciences, v. 58, p. 253-268, 2001.

COSTA, A. A. Cloud-ensemble simulations of atmospheric convection over the ocean. Part I: model description, coupled and uncoupled simulations of a TOGA-COARE case. Revista Brasileira de Meteorologia, v. 19, n. 3, p.227-236, 2004.

COSTA, A. A., SHERWOOD, S. Parcel model simulations of aerosol warm phase cloud microphysics interactions over the 
Amazon. Atmospheric Chemistry and Physics Discussion ,v. 5, p. 481-508, 2005.

FREUD, E.; ROSENFELD, D.; ANDREAE, M. O.; COSTA, A. A.; ARTAXO, P. Robust relation between $\mathrm{CCN}$ and the vertical evolution of cloud drop size distribution in deep convective clouds. Atmospheric Chemistry and Physics,v. 8, p. 1661-1675, 2008.

GRAY, W.; JACOBSON, R. W. Diurnal variation of deep cumulus convection. Monthly. Weather Review, v. 105, p. 1171-1188, 1977.

IPCC, 2007. Climate Change 2007: the physical Science Basis. Contribution of Working Group I to the Fourth Assessment Report of the Intergovernmental Panel on Climate Change. [Solomon, S., D. Qin, M. Manning, Z. Chen, M. Marquis, K. B. Averyt, M. Tignor and H. L. Miller (eds.)]. Cambridge University, Press, Cambridge, United Kingdon and New York, NY, USA, 996 pp.

MENON, S.; DEL GENIO, A. D.; KOCH, D.; TSELIOUDIS, G. GCM Simulations of the aerosol indirect effect: sensitivity to cloud parameterization and aerosol burden. Journal of the Atmospheric sciences, v. 59, p. 692-713, 2002.
MONCRIEFF, M. W.; KRUEGER, S. K.; GREGORY, D.; REDELSPERGER, J-L.; TAO, W.-K. GEWEX Cloud System Study (GCSS) Working Group 4: precipitating convective cloud systems. Bulletin of the American Meteorological Society, v. 78, n. 5, p. 831-845, 1997.

RANDALL, D. A.; HARSHVARDHAN; DAZLICH, D. A. Diurnal variability of the hydrologic cycle in a general circulation model. Journal of the Atmospheric Science. v. 48, p. 40-62, 1991.

RANDALL, D. A.; XU, K-M.; SOMERVILLE, R. J. C.; IACOBELLIS, S. Single-column models and cloud ensemble models as links between observations and climate models. Journal of Climate, v. 9, p. 1683-1697, 1996.

TWOMEY, S. Pollution and the planetary albedo. Atmospheric Environment. v. 8, p. 1251-1256, 1974.

WALKO, R. L.; COTTON, W. R.; MEYERS, M. P.; HARRINGTON, J. Y. New RAMS cloud microphysics parameterization Part I: the single-moment scheme. Atmospheric Research, v. 38, p. 29-62, 1995. 